\title{
Metabolites of Aquatic Cyanobacteria Represent a Unique Source of Biopharmaceutical
} Agents

\author{
${ }^{1}$ El Hanafi K.M., ${ }^{2}$ Badawi H. Mona and ${ }^{2}$ Waleed D. Saleh
}

${ }^{1}$ Microbiology Unit in Environment and Consumer Products Laboratory in Sharjah, United Arab Emirates.

${ }^{2}$ Department of Microbiology, Faculty of Agriculture, Cairo University 12613, Giza, Egypt

\author{
Received: 15 Jan. 2020 / Accepted 30 Mar. 2020 / Publication date: 20 April 2020
}

\begin{abstract}
Cyanobacteria constitute a vast potential resource in various applications such as pharmaceutical, agriculture, food, feed, fuel, fertilizer, industry and in combating pollution. In this study, the biodiversity of aquatic cyanobacteria was monitored in various water resources representing those of the River Nile at Giza and Ain Sokhna, Red sea in Egypt as well as some United Arab Emirates water supplies. Total number of six isolates were secured and subjected for morphological and microscopic examinations. Three isolates representing the most common members were identified using the molecular biology techniques. Those were closely related to the genera Anabaena sp., Oscillatoria sp. and Synechocystis sp. of the Gene Bank. They were evaluated for their potential capacities as anti-fungal and anti-bacterial agents as well as measuring their anti-oxidant activities. The examinations of chloroform, diethyl, hexane and methanol extracts of the tested cyanobacterial cultures indicated the presence of several metabolites including 9-hexadecenoic acid, leukotriene C4, neophytadiene, phthalic acid, hexadecanoic acid, octadecenoic acid, octasiloxane hexadecamethyl, phytol acetate, octadecadienoyl chloride and cyclohexasiloxane dodecamethyl. Adopting the disk diffusion method, the cyanobacterial extracts as anti-bacterial substances arranged the examined cultures in the descending order of Anabaena $>$ Synechocystis $>$ Oscillatoria with inhibition zone averages of 11.3, 10.7 and $10.3 \mathrm{~mm}$ respectively. Similarly, the experimented microbiota considerably varied in their anti-fungal capabilities where the cyanobacterium Anabaena seemed the most active one. In respect to the anti-oxidant activity, Oscillatoria was the pioneer among the other tested ones. All in all, this study supports the applicability of such very unique aquatic creatures in the biotechnological approaches and pharmaceutical ones in particular.
\end{abstract}

Keywords: Anabaena, Oscillatoria, Synechocystis, anti-bacterial, anti-fungal, anti-oxidant, GC-MS.

\section{Introduction}

Cyanobacteria are emerging from poisoning to healing. They have a long evolutionary history and constitute a unique group of ubiquitous oxygenic, photosynthetic bacteria that are capable of colonizing a vast diversity of ecological niches. It is therefore reasonable to assume that cyanobacteria have evolved to create a large pool of active compounds with diverse structures and functions. In fact, cyanobacteria's potential as a new source of bioactive molecules has been actively examined, mostly during the last two decades. Hundreds of cyanobacterial metabolites showed interesting and exciting biological activities, including anti-microbial, immunosuppressant, anti-alzaheimer and dementia risks, anti-cancer, anti-HIV (human immunodeficiency virus), anti-bacterial, anti-coagulant, antifungal, anti-inflammatory, anti-malarial, anti-protozoal, anti-tuberculosis, anti-viral and anti-tumor activities (Singh et al., 2011; Costa et al., 2012). However, despite their potent biological activities, cyanobacterial compounds have entered clinical trials, the most promising cyanobacterial secondary metabolites that have a vital role in medications.

In fact, nature has been recognised as an important source of potential drugs since ancient times, well before their active principles were first isolated and identified. Potent toxins such as atropine, morphine and colchicine were among the first active compounds to be isolated and some are still considered to be essential drugs in medical practice and health care systems. Throughout the $20^{\text {th }}$ century, many other life-saving drugs, including anti-biotics, immunosuppressant, anti-cancer drugs, compounds (vitamin B, Omega-3 fatty acids and a multi-nutrient combination named Fortasyn

Corresponding Author: El Hanafi K.M., Microbiology Unit in Environment and Consumer Products Laboratory in Sharjah, United Arab Emirates. 
Connect) as candidates for AD Management etc., have been developed from active human exploitation of natural sources. Even today, the majority of new chemical entities introduced as drugs in the market are derived or inspired from natural products (Newman and Cragg, 2012). This clearly demonstrates the central role that these compounds continue to play as major platforms for the discovery of new front-line drugs.

The drug authorities have been estimated that the pharmaceutical industry has to spend approximately 400 to 1800 million euros to bring a new chemical entity as a new drug into the market (Adams and Brantner, 2006) and such high costs are reflected in the scarcity of new drugs that are available for increasing numbers of diseases. The pharma industry is one of the upcoming industries with a market volume exceeding one trillion U.S. dollars (Mikulic, 2019).

Nowadays, several researches reported that Anabaena sp. Nostoc sp. Oscillatoria sp. and Synechocystis sp. produce some useful bio-products including carotenoids (especially $\beta$-carotene), astaxanthin, docosahexaenoic acid (DHA), eicosapentaenoic acid (EPA), bioactive and functional pigments, natural dyes, polysaccharides, anti-oxidants fischerindole L, fischerellin A, ambiguine isonitriles $\mathrm{A}-\mathrm{F}$, ambigol $\mathrm{A}$ and $\mathrm{B}$, tjipanazole $\mathrm{D}$, cyanovirin- $\mathrm{N}$, calothrixin $\mathrm{A}$, lyngbyatoxin $\mathrm{A}$, cryptophycin and algal extracts (Vijayakumar and Menakha, 2015; Bajpai, 2016; Dangi et al., 2017).

This study was designed to isolate and identify the dominant species of cyanobacteria from River Nile at Giza, Ain Sokhna, Red sea (Suez), Sharjah Memzer Lake, Dubai Memzer Lake in Arabin Gulf, Al Jazerah Al Hamra Sea in Al Fujeriah Emirate and Umm Al Quwain Sea Umm Al Quwain Emirate (United Arab Emirates). All the selected isolates were characterized and evaluated for their potential capacities to produce secondary metabolites that may have some biological activities.

\section{Material and Methods}

\section{Sampling sites}

Biodiversity of cyanobacterial communities of various aquatic environments of Egypt and United Arab Emirates was monitored in the present study. Twenty water samples were collected from different sites represented as follows: 1) two samples from River Nile, 2) two samples from Ain Sokhna in Red Sea's Gulf of Suze, 3) six samples from Sharjah Mamzer Lake in Arabian Gulf, 4) six samples from Dubai Mamzer Lake in Arabian Gulf, 5) two samples from Al Fujeriah, Al Jazerah Al Hamra Sea and 6) two samples from Umm Al Quwain Sea.

\section{Chemical profile of water samples}

The chemical composition of collected water samples included determination of the following parameters:

\section{a. pH and EC}

The pH and EC were measured according to APHA (1992) at Cyanobacteria Lab., Dept. Microbiology, Fac. Agric., Cairo University.

\section{b. T.S.S.}

Total soluble salts (T.S.S.) were determined (Page et al., 1989) at Central Lab., Fac. Science, Ain Shams University using to the following equation T.S.S $\left(\mathrm{mg}^{-1}\right)=$ E.C. $\times 640$.

\section{Enrichment culture of cyanobacteria}

The liquid enrichment cultures were prepared from the different water samples where 25 of water samples were aseptically added to $75 \mathrm{ml}$ of Allen and Arnon broth (Allen and Arnon, 1955) for fresh waters or BG11 broth (Rippka et al., 1979) for marine waters in 250 conical flasks. The inoculated flasks were incubated at $30{ }^{\circ} \mathrm{C}$ under continuous illumination, with Philips fluorescent white lamps, at a relatively low light intensity (400-600 lux).

\section{Purification of cyanobacterial isolates}

Isolates obtained from the different enrichment cultures of different samples were subjected to purification procedure applying various methods as follows: 


\section{a. Several successive transfers}

The isolated cyanobacteria, which previously grown in flasks containing Allen and Arnon liquid as well as BG11 media were successively sub-cultured several times on the same media and incubated for 3 - 4 weeks at $30^{\circ} \mathrm{C}$ until the healthy and homogenous cultures were obtained.

\section{b. Purification of cyanobacteria by UV. radiation}

Cyanobacterial cultures previously growing in flasks containing liquid media were sub-cultured in Petri dishes containing $50 \mathrm{ml}$ liquid media and incubated for 5-7 days at $30^{\circ} \mathrm{C}$. Those cultures were previously exposed to UV in UV cabinet SCIE-PLAS UV 4 PCR, UK. at Cyanobacteria Lab., Dept. Microbiology, Fac. Agric., Cairo University for 30,60 and 90 minutes. The produced growth was microscopically examined (Higazy, 1985).

\section{c. One filament-isolation}

This technique depends on gliding movement and phototaxis of cyanobacteria (Vaara et al., 1979). The nonaxenic cultures of cyanobacteria were grown on Allen and Arnon and BG11 agar media in Petri dishes to examine the ability of cyanobacterial filaments to grow and move toward a single source of light to pick a single filament of cyanobacteria. Once the single filament moved a sufficient distance on culture media, it was removed under sterilized conditions and placed into a separate flask containing fresh liquid Allen and Arnon as well as BG11 media. Pure isolates were maintained under photoautotrophic growth conditions in the same media.

\section{d. Media phases}

Isolates of cyanobacteria grown in conical flasks containing liquid media were sub-cultured by transferring $1 \mathrm{ml}$ of homogenous suspension from each strain to $25 \mathrm{ml}$ tubes containing $10 \mathrm{ml}$ of the respective medium. This technique was applied twice depending upon the solidity of media. The first, using solid / semi solid media phases, the second, using solid / liquid media phases of media used as the seeding layer of single filament of cyanobacteria. After incubation at optimum conditions, the single filament grown through the media above the second phase (liquid or semi-solid medium) and formed cyanobacterial layer/ mat on the surface of such medium (Higazy, 1985).

\section{Identification}

After wet mount preparation, the cyanobacteria morphotypes such as filamentous nature, size, shape of vegetative cells, presence of heterocyst and akinetes were examined, photographed using light microscope (Rippka et al., 1979), then Box PCR finger print technique (Rademaker and De Bruijn, 1997) was adopted. In addition, pigment composition of all isolates was determined.

\section{a. Morphological identification}

Several morphological properties were studied for all selected cyanobacterial cultures according to the characteristics described by Rippka et al. (1979).

\section{b. BOX-PCR finger prints}

The BOX-PCR finger prints of cyanobacteria were generated for the three selected isolates using BOXA1R primer (CTACGGCAAGGCGACGCTGACG). Eight $\mu$ l of the PCR products were separated by $1.5 \%$ agarose gel electrophoresis in $0.5 \mathrm{X}$ TBE-buffer for 4 hours $(50 \mathrm{~V})$. The BOXPCR finger print patterns were checked and compared visually.

\section{c. Genomic DNA extraction from cyanobacteria}

Cyanobacterial cells were harvested from Allen and Arnon as well as BG11 media by centrifugation at $10000 \mathrm{rpm}$ for $5 \mathrm{~min}$ then washed three times using $0.85 \% \mathrm{NaCl}$. Genomic DNA was extracted from cyanobacteria according to Devi et al. (2015). Cells were mechanically lysed in 2 $\mathrm{ml}$ eppendorf tubes filled with $1 \mathrm{~g}$ of glass powder by vigorously shaking for $1 \mathrm{~min}$ using bead beater. The yields of DNA were shaked using nanodrop spectrophotometer and agarose gel electrophoresis. 


\section{Pigment contents}

\section{a. Total chlorophyll and carotenoids}

Five $\mathrm{ml}$ of each culture were filtered through $0.47 \mu \mathrm{m}$ membrane filter using millipore filtration system. Three ml DMSO $95 \%$ were added to the filtrated cells in $10 \mathrm{ml}$ tube. The mixture was sonicated and incubated at $70{ }^{\circ} \mathrm{C}$ for $5 \mathrm{~min}$ in water bath then centrifuged at $3500 \mathrm{rpm}$ for 5 minutes. The optical density (OD) of the supernatant was measured at two different wave lengths (468 and 666 $\mathrm{nm}$ ) using spectrophotometer (Jenway, $6405 \mathrm{UV} / \mathrm{vis)}$ ) according to Seely et al. (1972). Total chlorophyll and total carotenoid concentrations were calculated using the following equations:

Total chlorophyll $\left(\mathrm{mg} \mathrm{l}^{-1}\right)=\mathrm{OD}_{666} \times \mathrm{D} \times \mathrm{F}$

where: $\mathrm{E}_{666}$, reading at $666 \mathrm{~nm}, \mathrm{D}$, volume of extract/volume of sample, F, 11.3 (factor to equal the reduction in absorbance).

Total carotenoids $\left(\mathrm{mg} \mathrm{l}^{-1}\right)=\mathrm{OD}_{468} \times \mathrm{D} \times \mathrm{F}$

where: $\mathrm{E}_{468}$, reading at $468 \mathrm{~nm}, \mathrm{D}$, volume of extract/volume of sample: $\mathrm{F}, 4.5$ (factor to equal the reduction in absorbance).

\section{b. Phycobiliproteins}

Cultures were sonicated for 40 seconds to break up filaments and release the water phycobiliprotein pigments, followed by centrifugation at $8000 \mathrm{rpm}$ to remove filament debris (Moares et al., 2010). The optical density (OD) of the supernatant was measured at the different wave lengths 562, 615 and $652 \mathrm{~nm}$ for phycoerythrin, phycocyanin and allophycocyanin, respectively. Phycobiliprotein concentrations were calculated according to the following equations in $\mu \mathrm{g} \mathrm{ml} \mathrm{m}^{-1}$ according to Bennett and Bogard (1973).

$$
\begin{gathered}
\text { Phycocyanin }(\mathrm{PC})=\mathrm{OD}_{615}-0.474\left(\mathrm{OD}_{652}\right) / 5.34 \\
\text { Allophycocyanin }(\mathrm{APC})=\mathrm{OD}_{652}-0.208\left(\mathrm{OD}_{615}\right) / 5.09 \\
\text { Phycoerythrin }(\mathrm{PE})=\mathrm{OD}_{562}-2.41(\mathrm{PC})-0.849(\mathrm{APC}) / 9.6
\end{gathered}
$$

\section{Cyanobacteria biomass yields}

Biomass concentrations of Anabaena, Oscillatoria and Synechocystis in each medium were estimated at 5 day intervals during the 40-day incubation period. Five $\mathrm{ml}$ of each culture medium were taken and filtered through a pre-weighed Whatman sterile membrane filters $(0.45 \mu \mathrm{m}$ cellulose acetate filter) and rinsed with $25 \mathrm{ml}$ of acidified distilled water $(\mathrm{pH} 4)$ to release all salts and nutrients. After filtration, filter papers were left to dry for 2 hours at $105^{\circ} \mathrm{C}$ and reweighed, then dry weight was calculated (AOAC, 2000).

\section{Preparation of microalgae extracts}

At the stationary phase of growth, 30-day old Anabaena, Oscillatoria and Synechocystis cultures were dried at $50{ }^{\circ} \mathrm{C}$ overnight. The dried biomass $(5 \mathrm{~g})$ was extracted with the solvents water, methanol, ethanol, acetone, chloroform, diethyl ether, ethyl acetate and hexane (HPLC grade). Extracts were sonicated for $20 \mathrm{~min}$ using ultrasonic microtip probe of $400 \mathrm{watt}$ and centrifuged at $4500 \mathrm{rpm}$ for $10 \mathrm{~min}$. Supernatants were retained and the pellets were re-extracted three times. Combined supernatants were evaporated to dryness at $40{ }^{\circ} \mathrm{C}$ using rotary evaporator. Dried extracts were stored in labeled sterile vials in a refrigerator till further use (Chauhan et al., 2010).

Anti-microbial screening by the disk diffusion method was applied for the determination of anti-microbial activity of the prepared extracts. Two working solutions of the extracts (5\% and $10 \%$ ) were prepared in dimethyl sulfoxide (DMSO). The yield of respective extract was cultured as: percentage yield $(\%)=$ dry weight of extract / dry weight of sample x 100 (NCCLS, 1997).

\section{Preparation of microbial cultures}

Six different clinical bacterial (Bacillus cereus ATCC 33018, Escherichia coli O157:H7 wild type strain 9311, Listeria monocytogenes ATCC, Pseudomonas aeruginosa ATCC 9027, Salmonella typhimurium ATCC 14028, Staphylococcus aureus ATCC 25923) and four fungal (Aspergillus flavus (NRRL 1957), Aspergillus niger (NRRL 326), Candida 
albicans (ATCC 10231), Macrophomina phascolina (NRRL 62743) strains were experimented for anti-microbial potentials of the cyanobacteria. Those candidates were obtained from Microbiology Lab., Faculty of Agriculture Research Park (FARP), Cairo University. Colonies $(24 \mathrm{~h})$ developed on tryptone glucose yeast extract agar, TGYE for bacteria and those of fungi (5-days old) on sabouraud dextrose agar, SD were picked up for inocula preparation in broth medium (Chandrasekaran et al., 2011).

\section{Anti-microbial activities}

\section{a. Anti-fungal effects}

The Sabouraud-dextrose agar medium (Chandrasekaran et al., 2011) was adopted to detect the anti-fungal properties of the crude extract. The medium consists of $(\mathrm{g} / \mathrm{l})$ : beef extract, 2; starch, 1.5; agar, 20 and $\mathrm{pH}, 5.6$ at $25{ }^{\circ} \mathrm{C}$. Freshly prepared inocula of test microorganisms were spread on agar plates. The media were incubated and at $25{ }^{\circ} \mathrm{C}$ for 5 days. Zone of inhibition (ZOI) as indicated by clear zone of microbial growth was measured.

\section{b. Anti-bacterial effects}

The tryptone glucose yeast extract agar, TGYE (Chandrasekaran et al., 2011) was used to detect the anti-bacterial properties of the crude extract. This medium comprises (g/l): peptone (meat and casein), 10; glucose monohydrate, 20; agar, 15; glucose, 15 and $\mathrm{pH}$ after sterilization, 5.6 at $25{ }^{\circ} \mathrm{C}$. Freshly prepared inocula of test microorganisms were spread on agar plates. The media were incubated at $35{ }^{\circ} \mathrm{C}$ for $24 \mathrm{~h}$. Zone of inhibition (ZOI) as indicated by clear zone of microbial growth was measured.

\section{Anti-oxidant activities}

DPPH Radical Scavenging Activity Assay: Quantitative measurement of radical scavenging activity of algal extracts was carried out according to the method described by Blois (1958). One $\mathrm{ml}$ of $0.1 \mathrm{~m} \mathrm{M} \mathrm{2,2-diphenyl-picrylhydrazyl} \mathrm{(DPPH)} \mathrm{solution} \mathrm{in} \mathrm{methanol} \mathrm{was} \mathrm{added} \mathrm{to} 3 \mathrm{ml}$ of methanolic extract prepared at different concentrations $\left(50-150 \mu \mathrm{g} \mathrm{ml}^{-1}\right)$. Butyl-4-hydroxyanisole (BHA) was used as a positive control. Discoloration was measured (in triplicate) at $517 \mathrm{~nm}$ after incubation for $30 \mathrm{~min}$. The capacity to scavenge the DPPH radical was calculated using the following equation: DPPH scavenging effect $(\%)=[\mathrm{ADPPH}-\mathrm{AS} / \mathrm{ADPPH}] \times 100$; where: ADPPH is the absorbance of the DPPH solution and AS is the absorbance of the solution when the sample extract was added (Abd El-Aty et al., 2014).

DPPH radical scavenging activity: The free radical scavenging activity was determined by DPPH scavenging assay. Aliquots of $100 \mu 1$ methanolic extract and $4 \mathrm{ml}$ of freshly prepared $0.1 \mathrm{mM}$ DPPH (1,1-Diphenyl-2-picrylhydrazyl) methanolic solutions were thoroughly mixed and kept for 20 min in the dark. The decrease of absorbance at $517 \mathrm{~nm}$ was read and expressed as $\mu$ mol gallic acid equivalent (GAE)/g dry weight (Rai and Rajashekhar, 2015). Instrument used: UV/Vis. Spectrophotometer, Jenway, England (Williams et al., 1995).

\section{Gas chromatography-mass spectrometry (GC-MS) analysis}

At the stationary phase of growth, 30-day old, Anabaena, Oscillatoria and Synechocystis cultures were harvested and dried in a hot air oven at $50{ }^{\circ} \mathrm{C}$ overnight. The chemical compositions of sample extracts were performed using Trace GC-ISQ mass spectrometer (Thermo Scientific, Austin, TX, USA) with a direct capillary column TG5MS (30 m x $0.25 \mathrm{~mm} \times 0.25 \mu \mathrm{m}$ film thickness). The column oven temperature was initially held at $50{ }^{\circ} \mathrm{C}$ then increased by $5{ }^{\circ} \mathrm{C} / \mathrm{min}$ to $250{ }^{\circ} \mathrm{C}$ hold for $2 \mathrm{~min}$. increased to the final temperature $310{ }^{\circ} \mathrm{C}$ by $25{ }^{\circ} \mathrm{C} / \mathrm{min}$ and hold for $2 \mathrm{~min}$. The injector and MS transfer line temperatures were kept at $270,260{ }^{\circ} \mathrm{C}$ respectively, Helium was used as a carrier gas at a constant flow rate of $1 \mathrm{ml} \mathrm{m^{-1 }}$. The solvent delay was $3 \mathrm{~min}$ and diluted samples of $2 \mu \mathrm{l}$ were injected automatically using auto sampler AS1310 coupled with GC in the split less mode. EI mass spectra were collected at $70 \mathrm{eV}$ ionization voltages over the range of m/z 50 650 in full scan mode. The ion source temperature was set at $250{ }^{\circ} \mathrm{C}$. The components were 
identified by comparison of their retention times and mass spectra with those of WILEY 09 and NIST 11 mass spectral database (Marín et al., 2016).

\section{Statistical analysis}

Results were subjected to one-way analysis of variance (ANOVA) of the general liner model (GLM) using SAS (1999), statistical package. All the experimental data are means of three replicates $(p \leq 0.05)$.

\section{Results and Discussion}

\section{Chemical analysis}

Water can be used for recreation, drinking, fisheries, agriculture or industry. Each of these uses has different defined chemical, physical and biological standards necessary to support that use. After many years of research, water quality standards are put in place to ensure the suitability of efficient use of water for a designated purpose. Water quality analysis is to measure the required parameters of water, following standard methods, to check whether they are in accordance with the standard (AOAC, 2000).

Table (1) presents salinity and acidity profiles in relation to cyanobacterial community. Apart from the sites of sampling, it could be observed that some water samples of Sharjah Memzer Lake and Dubai Memzer Lake exhibited the highest salinity levels represented by an average EC estimate of $56.09 \mathrm{dSm}^{-1}$.

Table 1: Chemical analyses of water samples and relative growth of autochthonous cyanobacteria

\begin{tabular}{|c|c|c|c|c|}
\hline Locations & $\begin{array}{c}\mathrm{EC} \\
(\mathrm{ppm})\end{array}$ & $\begin{array}{l}\text { T.S.S } \\
(\mathrm{g} / \mathrm{l})\end{array}$ & pH & $\begin{array}{l}\text { Relative } \\
\text { growth* }\end{array}$ \\
\hline \multicolumn{5}{|l|}{ River Nile } \\
\hline Giza water station (intake) & 41.00 & 20.00 & 7.06 & +++ \\
\hline Giza water station ( $20 \mathrm{~m}$ away) & 40.00 & 22.00 & 6.91 & +++ \\
\hline Red sea & & & & - \\
\hline Ain Sokhna (Site 1) & 15.45 & 7.78 & 6.70 & - \\
\hline Ain Sokhna (Site 2) & 15.70 & 7.76 & 6.60 & \\
\hline \multicolumn{5}{|l|}{ Arabin Gulf } \\
\hline \multicolumn{5}{|l|}{ Sharjah Memzer Lake } \\
\hline Site 1 & 56.08 & 59.990 & 8.06 & ++ \\
\hline Site 2 & 56.09 & 59.990 & 8.10 & ++ \\
\hline Site 3 & 56.08 & 59.981 & 8.13 & ++ \\
\hline Site 4 & 56.06 & 59.991 & 8.00 & ++ \\
\hline Site 5 & 56.07 & 59.990 & 8.05 & ++ \\
\hline Site 6 & 56.08 & 59.978 & 8.11 & ++ \\
\hline \multicolumn{5}{|l|}{ Dubai Memzer Lake } \\
\hline Site 1 & 56.09 & 59.989 & 8.13 & ++ \\
\hline Site 2 & 56.00 & 59.991 & 8.06 & ++ \\
\hline Site 3 & 56.08 & 59.989 & 8.11 & ++ \\
\hline Site 4 & 56.09 & 59.979 & 8.09 & ++ \\
\hline Site 5 & 56.09 & 59.989 & 8.04 & ++ \\
\hline Site 6 & 56.08 & 59.978 & 8.08 & ++ \\
\hline \multicolumn{5}{|l|}{ Al Fujeriah } \\
\hline \multicolumn{5}{|l|}{ Al Jazerah Al Hamra Sea } \\
\hline Site 1 & 56.06 & 59.990 & 8.08 & + \\
\hline Site 2 & 56.08 & 59.991 & 8.12 & + \\
\hline \multicolumn{5}{|l|}{ Umm Al Quwain Sea } \\
\hline Site 1 & 56.03 & 59.989 & 8.01 & - \\
\hline Site 2 & 56.04 & 59.990 & 8.03 & - \\
\hline
\end{tabular}

*, -, no growth, +, weak growth, ++, good growth, +++ , dense growth.

On the contrary, water samples of Giza showed as low as $40.00-41.00 \mathrm{dSm}^{-1}$, other water samples recorded EC values ranged from 40.00 to $56.09 \mathrm{dSm}^{-1}$. Variations in salinity levels 
of the different water samples are expressed, as well as total soluble salts (TSS) where samples of Al Jazerah Al Hamra Sea, Al Jazerah Al Hamra Sea and Sharjah Memzer Lake, area contained the highest quantities of salts, (59.98-59.99 ppm), water samples of Dubai Memzer Lake ranked the second. Compared to other waters, samples taken from Ain Sokhna site were the least salted ones having TSS of $(7.76-7.78 \mathrm{ppm})$. In respect to $\mathrm{pH}$ of tested waters, the estimates hardly fluctuated from site to another, but generally they were near the natural side of neutrality. In the majority of cases, $\mathrm{pH}$ not exceeded 8.13.

\section{Enrichment, isolation, purification and characterization}

Microscopic examinations of original water samples, obtained from all locations, indicated low densities of cyanobacteria belonging to different species. This is most likely due to deficiency of some essential and / or trace elements required for growth of cyanobacteria. Therefore, Allen and Arnon medium (Allen and Arnon, 1955) was used to stimulate their growth in water samples. Results of enrichment cultures for water samples indicated the considerable presence of cyanobacteria. Isolates were obtained and subjected to purification and characterization including several successive transfers, one filament technique and UV exposure. Due to their rapid growth and recovery from UV exposure, as well as their healthy appearance in their liquid cultures, three different representative isolates were selected (Fig. 1). The Box-PCR finger prints of cyanobacteria were generated for the three secured isolates (Fig. 2) according to Rademaker and De Bruijn (1997), using BOXA1R primer (CTACGGCAAGGCGACGCTGACG). The finger print profiles showed high similarty with Anabaena sp. and Oscillatoria sp. and Synechocystis sp. in the Gene Bank. Similarly, Rippka et al. (1979) successfully isolated these three different genera from various aquatic environments. Also, Uyede et al. (2016) reported that cyanobacterial genera of Anabaena, Oscillatoria and Synechocystis were found in terrestrial, fresh water and marine environments.
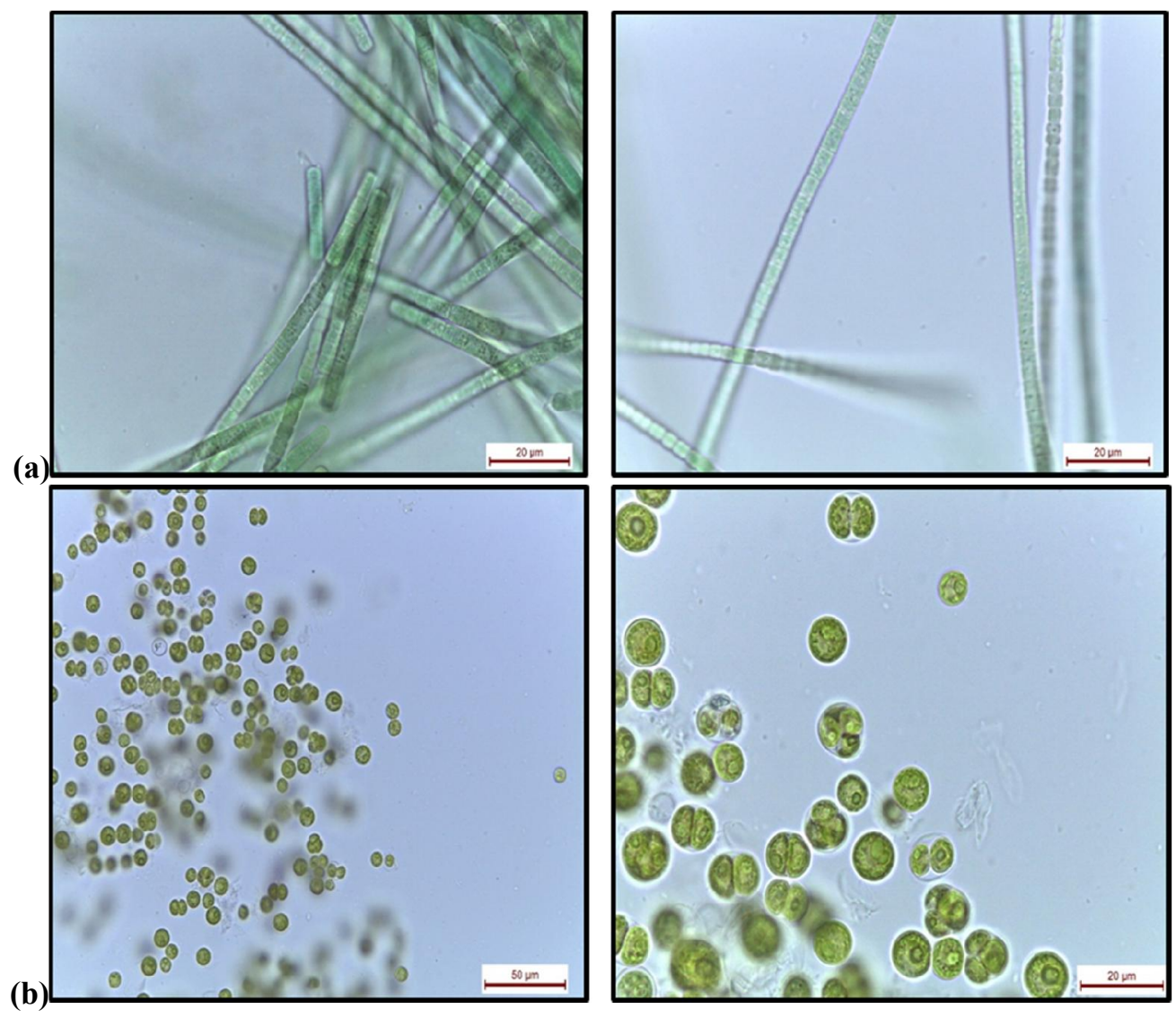
Middle East J. Agric. Res., 9(2): 253-269, 2020

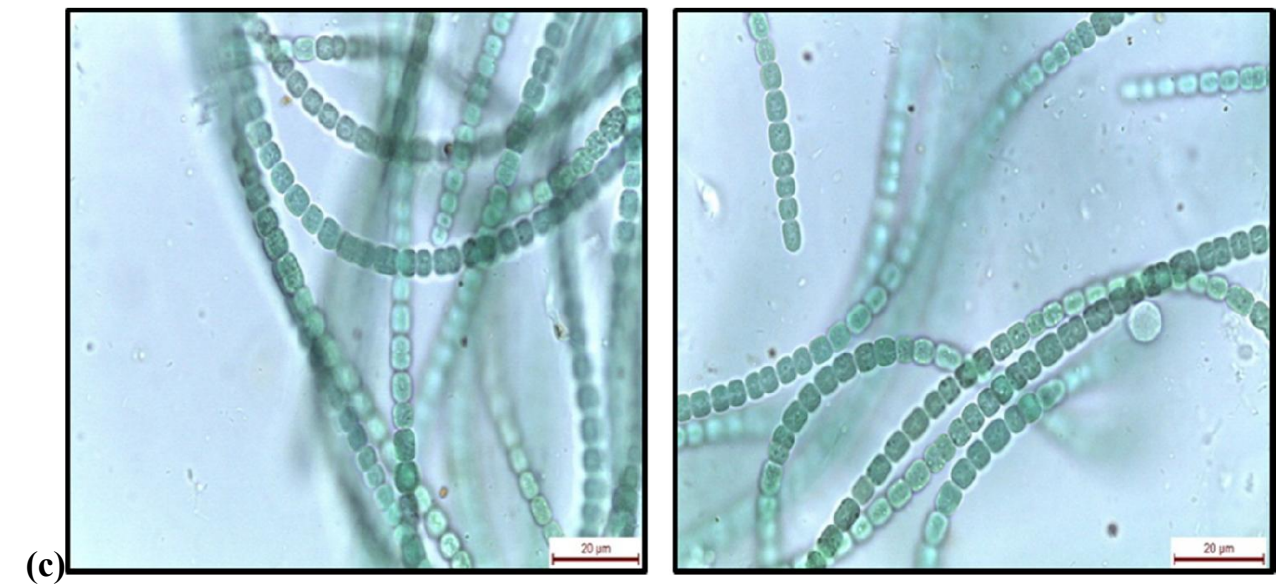

Fig. 1: Photographs $(400 \mathrm{x})$ of 30-day old cultures of Anabaena (a), Oscillatoria (b) and Synechocystis (c).

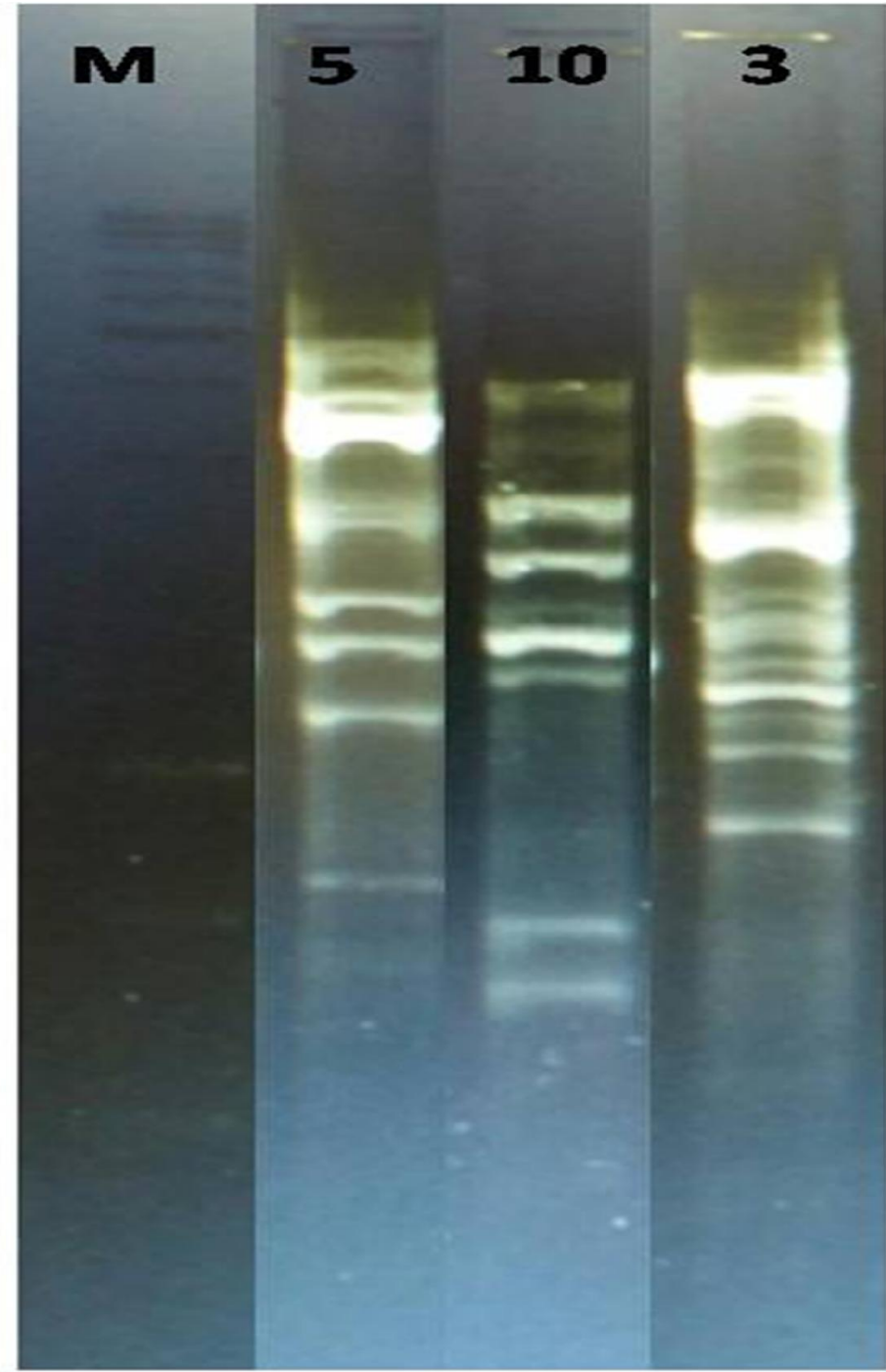

Fig. 2: BOX-PCR finger prints profiles of Oscillatoria (5), Synechocystis (10) and Anabaena (3). 


\section{Dry weight}

Among the dry weights of cyanobacterial cultures, when the different solvents used for compound extraction, aqueous extracts of all tested cultures showed the highest dry weight values $52.0-115.9 \mathrm{mg} \mathrm{g}^{-1} \quad$ (Table 2). In contrast, all cultures showed the lowest dry weights when diethyl ether solvent was used for compound extraction with average of $39.0 \mathrm{mg} \mathrm{g}^{-1}$. Regardless of the solvent type and concerning the amounts of dry weights of cyanobacterial cultures, they could be descendingly arranged in the following order: Oscillatoria $>$ Anabaena $>$ Synechocystis.

Table 2: Dry weight of crude extracts from dried cyanobacteria biomass

\begin{tabular}{lccccc}
\hline \multirow{2}{*}{ Cyanobacterial strains } & \multicolumn{4}{c}{ Crude extracts mg $^{-1}$ (Mean**S.E) } \\
& Aqueous & MeOH $^{*}$ & CH $_{3} \mathbf{C l}^{*}$ & DEE* $^{*}$ & Hexane \\
\hline Oscillatoria & $82.7 \pm 0.14$ & $55.7 \pm 0.28$ & $38.0 \pm 0.14$ & $54.4 \pm 0.28$ & $4.5 \pm 0.04$ \\
Anabaena & $52.0 \pm 0.28$ & $10.7 \pm 0.11$ & $51.6 \pm 0.11$ & $44.7 \pm 0.42$ & $12.8 \pm 0.14$ \\
Synechocystis & $115.9 \pm 0.21$ & $54.0 \pm 0.14$ & $38.1 \pm 0.21$ & $17.9 \pm 0.11$ & $3.5 \pm 0.04$ \\
\hline
\end{tabular}

$\mathrm{n}=3 ; \mathrm{MeOH}$, methanol; $\mathrm{CH}_{3} \mathrm{Cl}$, chloroform; DEE, diethyl ether.

\section{Anti-fungal activities}

Concerning the anti-fungal activities of cyanobacterial cultures against the tested fungal species, results indicated that the maximum inhibition zone of $6.3 \mathrm{~mm}$ was observed against Macrophomina phascolina using the aqueous solvent for extraction of Anabaena compounds (Table 3). Irrespective of both tested fungal species and applied solvents, inhibition zones were not detected in cyanobacterial extracts of Oscillatoria and Synechocystis.

Table 3: Anti-fungal activities of Anabaena crude extracts against mycotoxingenic fungi

\begin{tabular}{lccccc}
\hline Fungal strains & $\begin{array}{c}\text { Negative } \\
\text { control }\end{array}$ & $\begin{array}{c}\text { Positive } \\
\text { control }\end{array}$ & Chloroform & MeOH & Aqueous \\
\hline Aspergillus flavus & 0.00 & $14.1 \pm 0.54$ & 0.00 & 0.00 & 0.00 \\
Aspergillus niger & 0.00 & $10.8 \pm 0.76$ & 0.00 & 0.00 & 0.00 \\
Candida albicans & 0.00 & $10.4 \pm 0.58$ & 0.00 & 0.00 & 0.00 \\
Macrophomina phascolina & 0.00 & $11.1 \pm 0.24$ & 0.00 & $6.2 \pm 0.76$ & $6.3 \pm 1.80$ \\
\hline
\end{tabular}

$\mathrm{n}=3$; negative control, DMSO, Dimethyl sulfoxide; positive control, Nystatin; $\mathrm{CH}_{3} \mathrm{Cl}$, chloroform; $\mathrm{MeOH}$, methanol.

\section{Anti-bacterial activities}

Concerning the anti-bacterial activities of all cyanobacterial cultures against the tested bacterial species, results in Tables (4, 5, and 6) indicated that the maximum inhibition zones of 10.02-11.30 $\mathrm{mm}$ were observed against Listeria monocytogenes. In general cyanobacterial extracts could be arranged in descending order of: Anabaena $>$ Synechocystis $>$ Oscillatoria cultures with inhibition zone averages of $11.3,10.7 \mathrm{~mm}$ and $10.3 \mathrm{~mm}$ respectively.

Table 4: Anti-bacterial activities of Anabaena crude extracts against mycotoxigenic bacteria

\begin{tabular}{lccccc}
\hline Bacterial strains & $\begin{array}{c}\text { Negative } \\
\text { control }\end{array}$ & $\begin{array}{c}\text { Positive } \\
\text { control }\end{array}$ & Chloroform & MeOH & Aqueous \\
\hline Bacillus cereus & 0.00 & $14.1 \pm 0.54$ & 0.00 & 0.00 & 0.00 \\
Escherichia coli & 0.00 & $10.8 \pm 0.76$ & 0.00 & 0.00 & 0.00 \\
Listeria monocytogenes & 0.00 & $10.4 \pm 0.58$ & 0.00 & $11.3 \pm 1.80$ & $10.2 \pm 1.53$ \\
Pseudomonas aeruginosa & 0.00 & $11.1 \pm 0.24$ & 0.00 & 0.00 & 0.00 \\
Salmonella typhimurium & 0.00 & $14.1 \pm 0.54$ & 0.00 & 0.00 & 0.00 \\
\hline n=3; negative control, DMSO, Dimethyl sulfoxide; positive control, Nystatin; $\mathrm{CH}_{3} \mathrm{Cl}$, chloroform; $\mathrm{MeOH}$, methanol.
\end{tabular}

Table 5: Anti-bacterial activities of Oscillatoria extracts against mycotoxigenic bacteria

\begin{tabular}{lccccc}
\hline Bacterial strains & $\begin{array}{c}\text { Negative } \\
\text { control }\end{array}$ & $\begin{array}{c}\text { Positive } \\
\text { control }\end{array}$ & Chloroform & MeOH & Aqueous \\
\hline Bacillus cereus & 0.00 & $14.1 \pm 0.54$ & 0.00 & 0.00 & 0.00 \\
Escherichia coli & 0.00 & $10.8 \pm 0.76$ & 0.00 & 0.00 & 0.00 \\
Listeria monocytogenes & 0.00 & $10.4 \pm 0.58$ & 0.00 & $10.3 \pm 1.80$ & $10.2 \pm 1.53$ \\
Pseudomonas aeruginosa & 0.00 & $11.1 \pm 0.24$ & 0.00 & 0.00 & 0.00 \\
Salmonella typhimurium & 0.00 & $14.1 \pm 0.54$ & 0.00 & 0.00 & 0.00 \\
\hline
\end{tabular}

$\mathrm{n}=3$; negative control, DMSO, Dimethyl sulfoxide; positive control, Nystatin; $\mathrm{CH}_{3} \mathrm{Cl}$, chloroform; $\mathrm{MeOH}$, methanol. 
Table 6: Anti-bacterial activities of Synechocystis extracts against mycotoxigenic bacteria

\begin{tabular}{lccccc}
\hline Bacterial strains & $\begin{array}{c}\text { Negative } \\
\text { control }\end{array}$ & $\begin{array}{c}\text { Positive } \\
\text { control }\end{array}$ & Chloroform & MeOH & Aqueous \\
\hline Bacillus cereus & 0.00 & $14.1 \pm 0.54$ & 0.00 & 0.00 & 0.00 \\
Escherichia coli & 0.00 & $10.8 \pm 0.76$ & 0.00 & 0.00 & 0.00 \\
Listeria monocytogenes & 0.00 & $10.4 \pm 0.58$ & 0.00 & $10.7 \pm 1.80$ & $10.5 \pm 1.53$ \\
Pseudomonas aeruginosa & 0.00 & $11.1 \pm 0.24$ & 0.00 & 0.00 & 0.00 \\
Salmonella typhimurium & 0.00 & $14.1 \pm 0.54$ & 0.00 & 0.00 & 0.00 \\
\hline
\end{tabular}

$\mathrm{n}=3$; negative control, DMSO, Dimethyl sulfoxide; positive control, Nystatin; $\mathrm{CH}_{3} \mathrm{Cl}$, chloroform; $\mathrm{MeOH}$, methanol.

\section{Anti-oxidant activities}

Anti-oxidants in the extracts of cyanobacteria isolates reduced DPPH radical to DPPH-H which indicated the potential to be an H-atom donor (Abd El-Baky et al., 2007). Remarkably, cyanobacteria isolates showed diverse anti-oxidant activities. Data in Table (7) revealed that the cyanobacterium Oscillatoria exhibited the highest anti-oxidant activities (average of $45.64 \% \mathrm{DPPH}$ ) followed by Anabaena (40.85 \% DPPH) then Synechocystis (40.55 \% DPPH).

Table 7: Anti-oxidant activities extracts of Anabaena, Oscillatoria and Synechocystis

\begin{tabular}{lccc}
\hline \multirow{2}{*}{ Cyanobacterial strain } & \multicolumn{3}{c}{ \% DPPH Redical-Scavening Activity } \\
& $\mathbf{0 . 1} \%$ & $\mathbf{0 . 5} \%$ & $\mathbf{5 \%}$ \\
\hline Anabaena & 15.30 & 20.70 & 86.56 \\
Synechocystis & 15.58 & 20.96 & 85.12 \\
Oscillatoria & 18.41 & 29.18 & 89.32 \\
\hline
\end{tabular}

The anti-oxidant activities of cyanobacterial species proved that their crude extracts contained both the electron and hydrogen atom donating ability. The extracts containing anti-oxidants such as phenolic compounds are able to donate hydrogen atom to the free radical thus stopping the propagation chain reaction during lipid oxidation process (Abd El-Baky et al., 2009). It is known that prevention of the chain initiation step by scavenging various reactive species such as free radicals is considered to be important mode of action (Ruberto et al., 2001).

\section{GC-MS analysis and compound identification}

Since the different cyanobacterial cultures, obtained during this study, proved to have variable cytotoxicities against several microorganisms, it was necessary to identify the responsible compounds for such activities. This was performed by comparison of their retention times and mass spectra with those of WILLEY 09 and NIST 11 mass spectral database using Trace GC Ultra- ICQ Mass Spectrometer (Figs. 3 - 5). Total numbers of 71, 73 and 102 compounds were detected in the extracts of Synechocystis, Anabaena and Oscillatoria cultures (data not shown). Regardless of either cyanobacterial isolate or extraction solvent, Figure (6) illustrates the most common bioactive metabolites produced by the investigated cyanobacterial members. A vast array of literature (Padam et al., 2019; Konstantinou et al., 2020) proved that these compounds have diverse effects including antialzheimer, anti-diabetic, anti-tumor, anti-inflammatory, anti-oxidant and anti-microbial activities. These metabolites can be utilized in fields of biotechnology and pharmaceuticals industry as well as production of several bioactive compounds (Abdo et al., 2012; Malathi et al., 2014; Shaieb et al., 2014; Semary and Fouda, 2015). So, due to their high pharmaceutical value, a new point of making use of cyanobacteria to rise up is progressively increased (Bassant et al., 2018). When produced compounds by individual cultures were compared, some interesting observations were found. For example, each culture was distinguished by production of certain compounds while the others were not. Here, only Oscillatoria produced leukotriene C4, p entadecane, ipriflavone, docosane, octadecane, eicosan, hexadecane, tetradecanol, dotriacontane and octadecyl. Meanwhile; cyclohexasiloxane, dodecamethyl, minocycline, hexadecanoic acid, methyl ester, phthalic acid and heptacosane were produced only by Anabaena and ethyl oleate, undecane and cyclopropaneoctanoic acids were produced only by Synechocystis. Some compounds were commonly produced by more than one culture i.e decane, 2,5-cyclohexadien, 9-octadecanoic acid (Z) and 2,5 cyclohexadien were produced by Oscillatoria and Anabaena, eicosane, propanedioic acid and ethyl 6-cyano-2- methoxy3- methyl-2h- pyran-4-carboxylate were produced by Oscillatoria and Synechocystis while 9,12octadecadienoyl chloride, (z,z), and 2,5-cyclohexadien were produced by Anabaena and Synechocystis. 


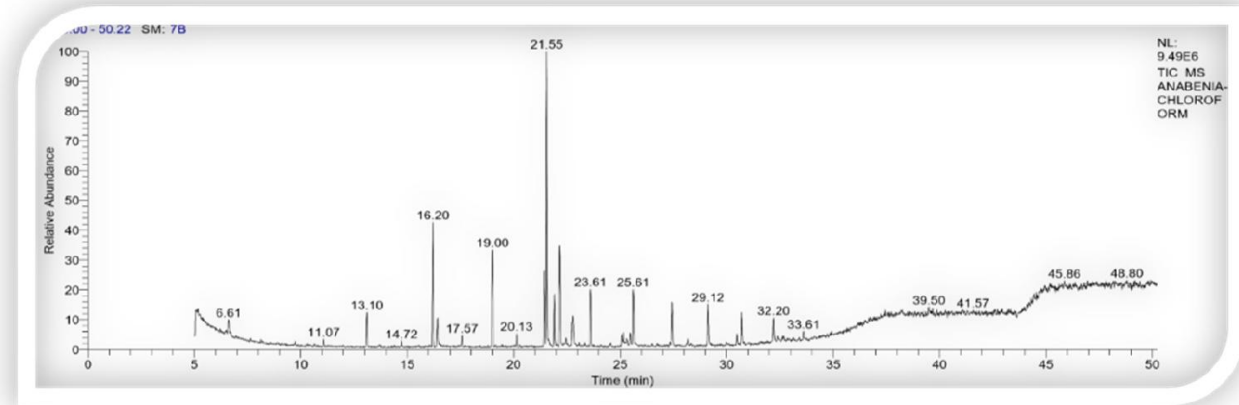

(a)

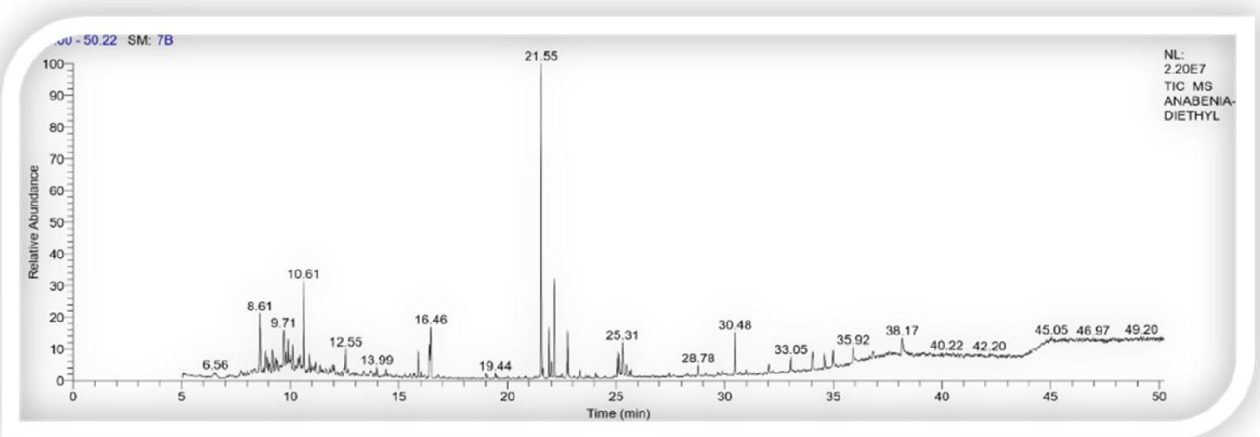

(b)

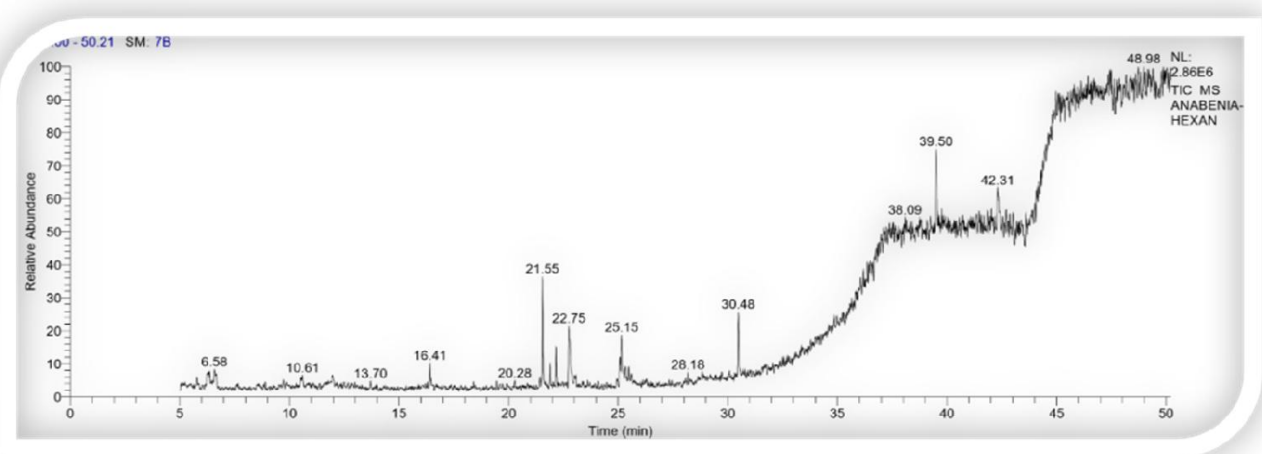

(c)

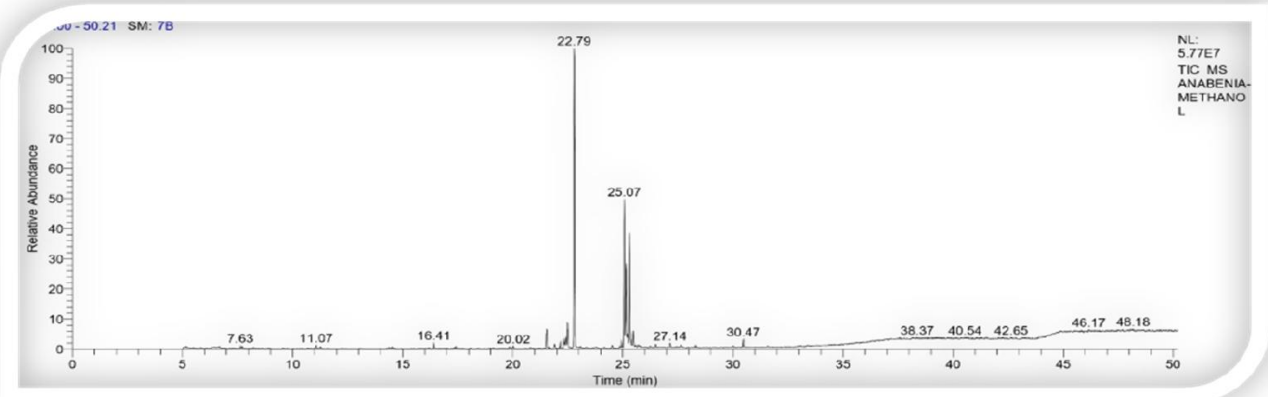

(d)

Fig. 3: Chromatograms representing the chemical compounds produced in the various extracts of Anabaena culture, a) chloroform, b) diethyl ether, c) hexane and d) methanol. 


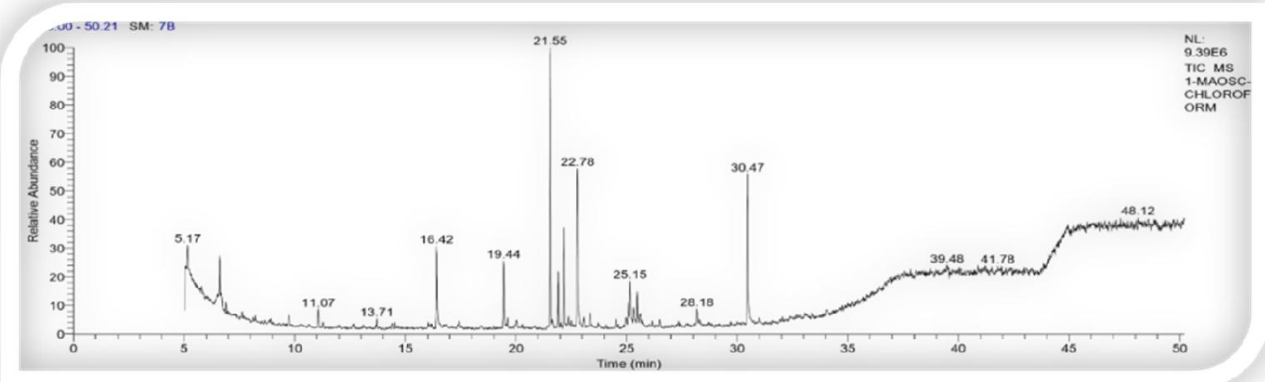

(a)

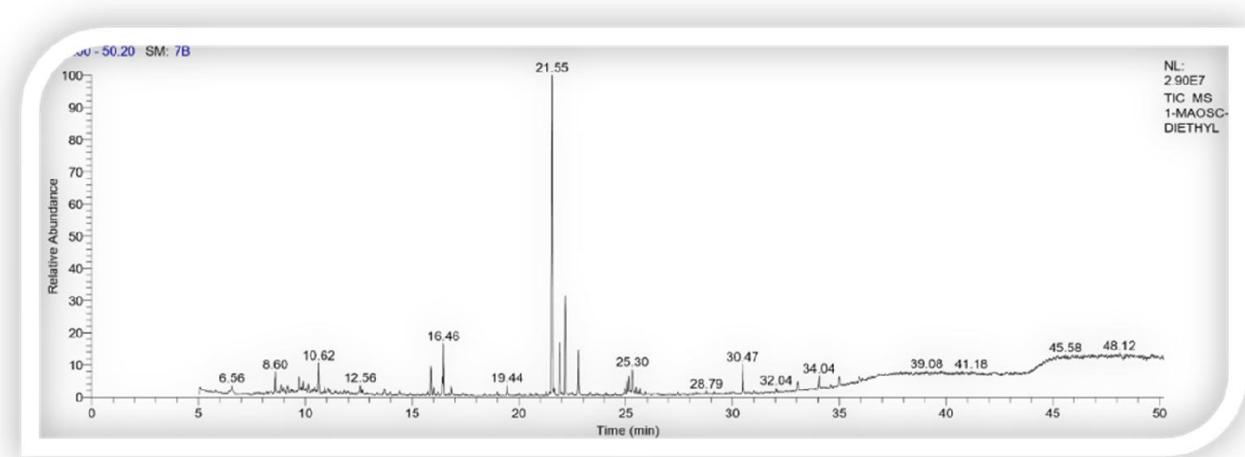

(b)

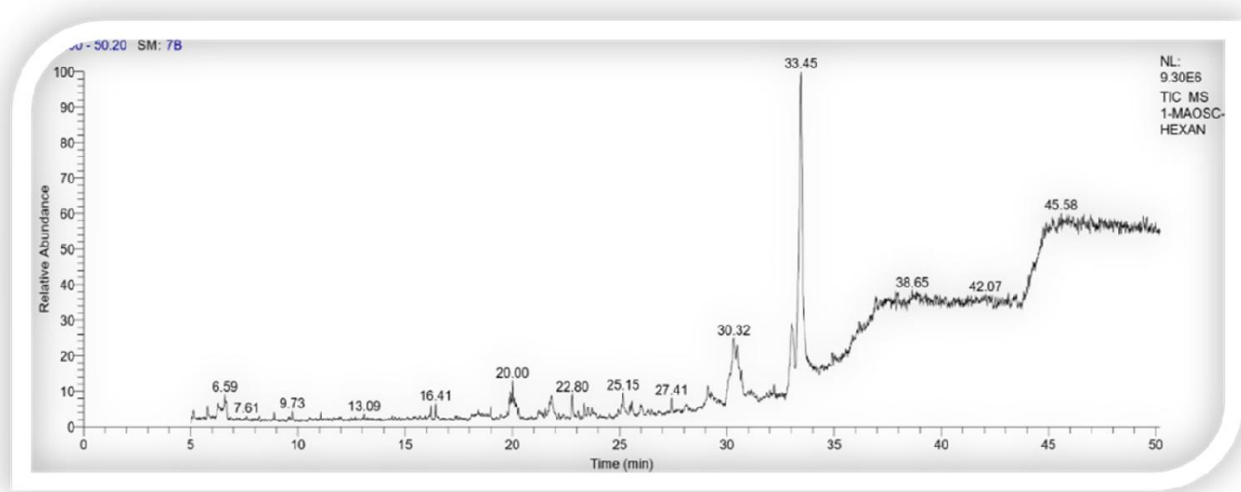

(c)

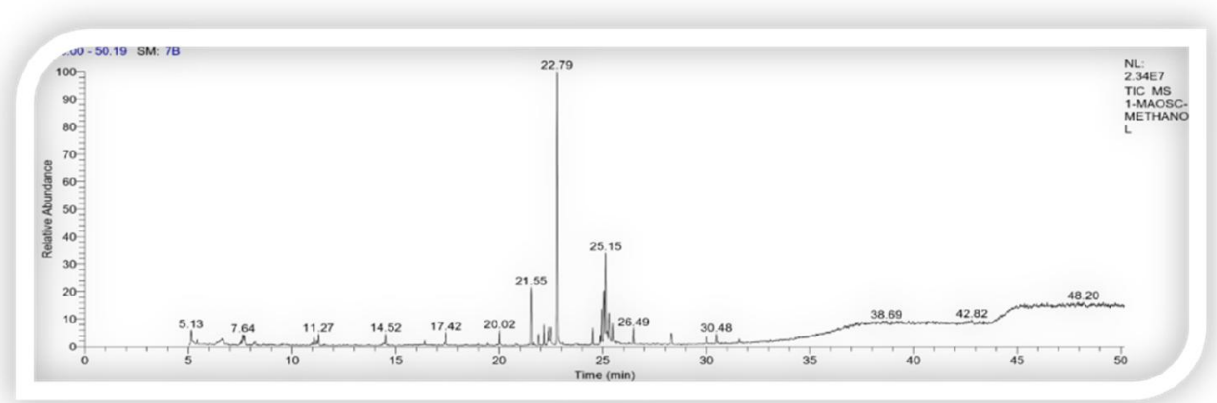

(d)

Fig. 4: Chromatograms representing the chemical compounds produced in the various extracts of Oscillatoria culture, a) chloroform, b) diethyl ether, c) hexane and d) methanol 


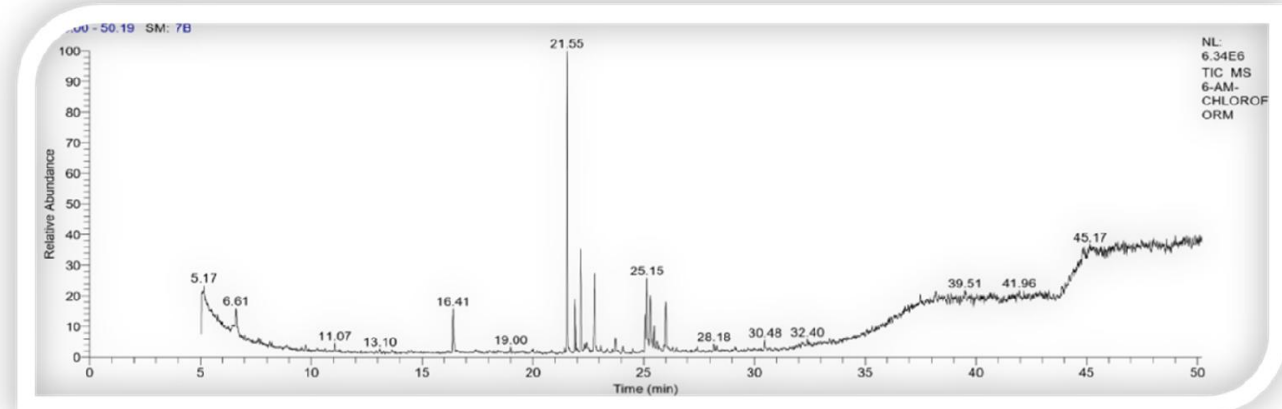

(a)

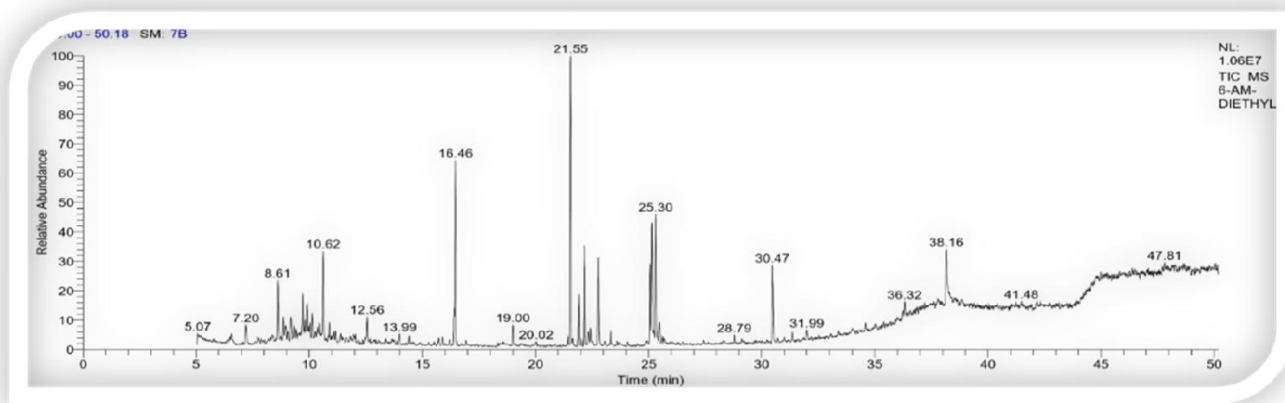

(b)

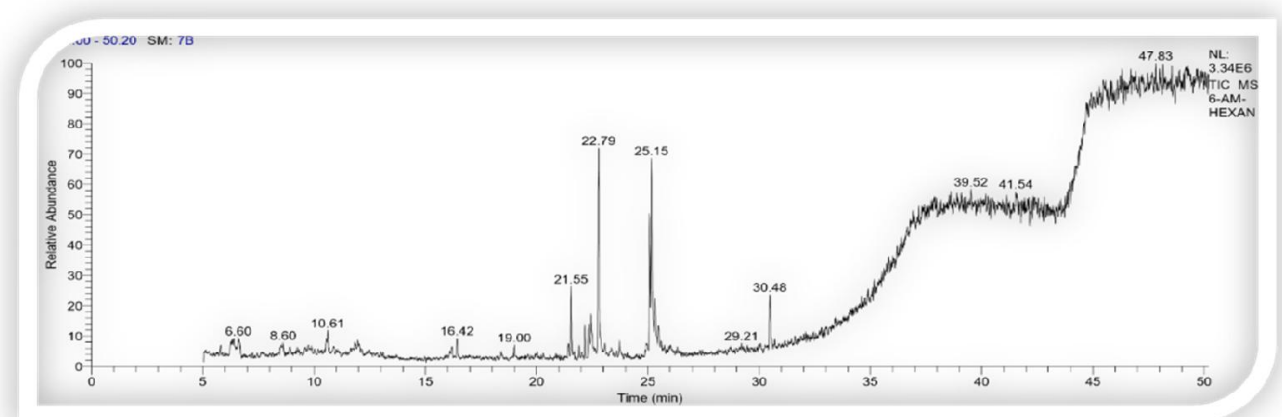

(c)

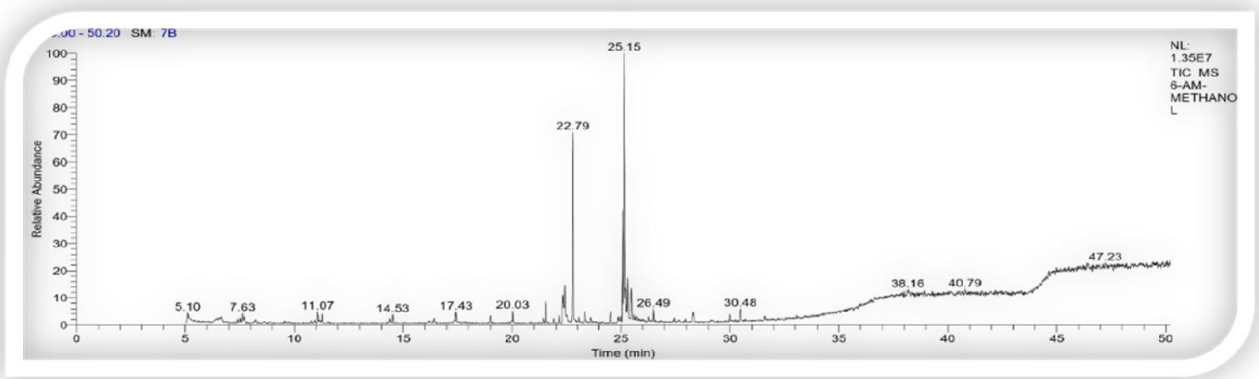

(d)

Fig. 5: Chromatograms representing the chemical compounds produced in the various extracts of Synechocystis culture, a) chloroform, b) diethyl ether, c) hexane and d) methanol 


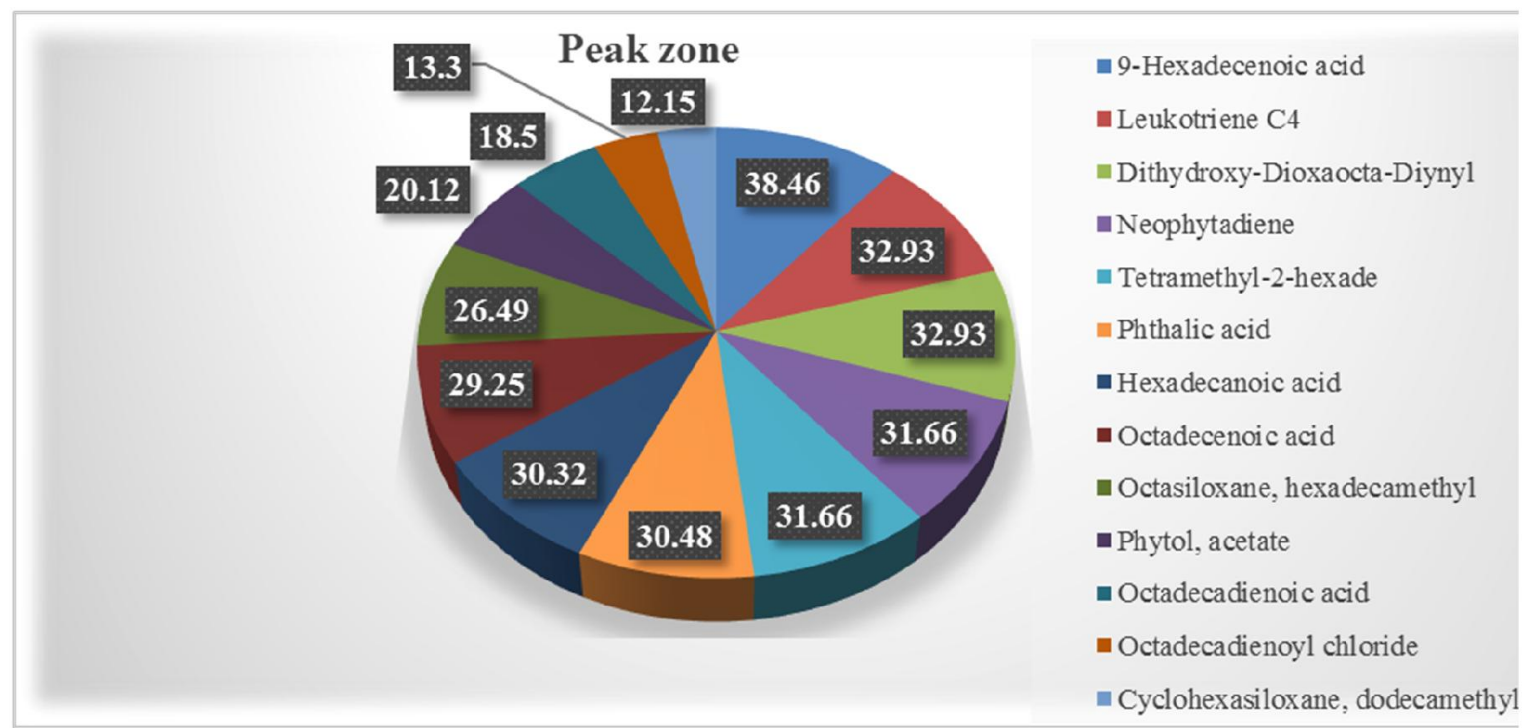

Fig. 6: Bioactive compounds detected in cultures tested related with high peak zone.

Eicosan was reported to have anti-bacterial, anti-tumor and cytotoxic effect (Belkhdar et al., 2015). Devi and Mehta (2016) indicated that heptadecane was found in Anabaena and Synechocystis extracts and it is known for its anti-cancer, anti-oxidant and anti-microbial activities. In addition, it has been demonstrated that a little is known about the mechanisms by which nonadecanoic acid inhibit cancer growth and methyl oleate anti-gastric and anti-oxidant (Carrillo et al., 2012).

However, Mericli et al. (2017) found that when fatty acids, mainly oleic and linoleic acids were added to the diet, increased HDL-cholesterol and reduced LDL-cholesterol as well as improved body weight control and reduced the risk of obesity-related health disorders such as heart disease and type II diabetes. At the same time, hexadecanoic acid was also produced from ethanol extract of the aquatic plant Eichormia crassipon and proved to have anti-androgenic effect (Tyagi and Agarwal, 2017). Meanwhile, Gillatt (2006) reported that anti-androgen is used in treatment of prostate cancer and prostate enlargement in male as well as treatment of acne and polycystic ovary syndrome in females. Also, phytol was reported to be used as a precursor for the manufacture of synthetic forms of vitamin E (Netscher, 2007) and vitamin K (Daines et al., 2003).

Recently, phytol was found to act as anti-inflammatory anti-cancer (Tyagi and Agarwal, 2017) and improved immunological response against tumor in a very beginning stage of carcinogenesis (Singh et al., 2017). Additionally, data revealed that ibuprofen, 10-octadecanoic acid methyl ester and hexadecanoic acid methyl were previously reported to have anti-inflammatory, anti-oxidant and antifungal activities (Belkhdar et al., 2015).

Similar to what detected in cyanobacterial cultures during this study, Arora et al. (2017) reported the presence of several bioactive compounds in roots of the economic plant Cenchrus ciliaris in India. Some of these compounds were hexadecane, eicosan, nonadecane, phytol and many others. They concluded that such secondary metabolites are commercially important and are used in pharmaceutical industry.

It is very palpable that therapeutically drugs such as anti-infective, anti-oxidants and antialzheimer have paved the way for modern medicine. Some drugs may have excellent efficacy but can have very serious side effects. The majority of therapeutically drugs in current use are based on natural products which are extracted from cyanobacteria. Pharmaceutical companies have neglected both the search for novel treatments and natural product-based drug discovery over many years. The secondary metabolism of cyanobacteria has been studied extensively over many decades and many indispensable drug substances in many therapeutic areas have been approved they are based on compounds originally isolated from these organisms and showed a broad spectrum of activities, such as antitumor, anti-bacterial and antiviral effects and protease inhibition. 
Based on the results of this study, the application of cyanobacteria was found to be very effective as anti-bacterial, anti-fungal, anti-oxidant compounds and cyanobacteria strains such as Anabaena, Oscallotoria and Synechocystis play an important role in integrated disease management.

\section{References}

Abd El-Aty, M.A.M., A.A. Mohamed and A.F. Samhan, 2014. In vitro anti-oxidant and anti-bacterial activities of two fresh water cyanobacterial species, Oscillatoria agardhii and Anabaena sphaerica. J. of Appl. Pharma. Sci., 4(7): 69-75.

Abd El Baky, H. H., F.K. El Baz, and G.S. El-Baroty, 2007. Production of carotenoids from marine microalgae and its evaluation as safe food colorant and lowering cholesterol agents. Am. Eurasian J. Agric. Environ. Sci., 2: 792-800.

Abd El-Baky, H.H., F.K. El-Baz and G.S. El-Baroty, 2009. Enhancement of anti-oxidant production in Spirulina platensis under oxidative stress. Acta. Physiol. Plant, 31: 623631.

Abdo, S.M., H.H. Mona, M.E. Waleed, A.S. Rawheya, and H.A. Gamila, 2012. Antiviral activity of freshwater algae. J. Appl. Pharm. Sci., 2: 21-25.

Adams, C.P. and V.V. Branter, 2006. Estimating the cost of new drug development: is it really $\$ 802$ million? Health affairs. 25(2): 420-428.

Allen, M. B. and D.I. Arnon, 1955. Growth and nitrogen fixation by Anabaena cylindrical. Plant Physiol., 30: 366-372.

AOAC, 2000. Analysis of the Association of Official Analytical Chemists. $17^{\text {th }}$ ed., Gaithersburg, MD, USA, pp. 74-144.

APHA, American Public Health Association, 1992. Standard methods for the examination of water and wastewater, $18^{\text {th }}$ ed., APHA, $541 \mathrm{p}$.

Arora, S., G. Kumar and M. Sonam, 2017. Gas chromatography-mass spectroscopy analysis of root of an economically important plant, Cenchrus ciliaris L. from Thar Desert, Rajasthan (India). Asian J. Pharm. Clin. Res., 10(9): 64-69.

Bajpai, V.V., 2016. Anti-microbial bioactive compounds from marine alge: A mini review, Indian J. Geo-Marine Sci. 45 (9): 1076-1085.

Bassant, E. Ahmed, Badawi, H. Mona, Mostafa S. Soha and A.M. Higazy, 2018. Human anti-cancers and anti-diabetic activities of the cyanobacterium Fischerella sp. BS1-EG isolated from River Nile, Egypt. Int. J. Curr. Microbiol. App. Sci., 7(1): 3473-3485.

Belkhdar, G., A. Benjouad, and E.H. Abd Ennebi, 2015. Determination of some bioactive chemical constituents from Thesium humile vahl, J. Matar. Environ. Sci., 6(10): 27782783.

Bennett, A. and L. Bogard, 1973. Complementary chromatic adaptation in filamentous blue-green algae. J. Filament. Biol., 58: 419-438.

Blois, M.S., 1958. Anti-oxidant determinations by the use of a stable free radical. Nature, 181: 1199-1200.

Carrillo, C., M. Cavia del, and S.R. Alonso-torre, 2012. Antitumor effect of olic acid mechanisms of action. A review. Nutr. Hosp., 27 (5): 1860-1865.

Chandrasekaran M., A. Senthilkumar and V. Venkatesalu, 2011. Anti-bacterial and antifungal efficacy of fatty acid methyl esters from the leaves of Sesuvium portulacastrum L. European Rev. Med. Pharmacol. Sci., 15: 775.

Chauhan, A., G. Chauhan, P. Gupta, P. Goyal and P. Kaushik, 2010. In vitro anti-bacterial evaluation of Anabaena sp. against several clinically significant microflora and HPLC analysis of its active crude extracts. Indian J. Pharm., 42: 105-107.

Costa, M.J., R.M.H. Costa, P. Fernandes, V. Barros, Vasconclos and R. Martins, 2012. Marine cyanobacteria compounds with anti-cancer properties: A review on the implication of apoptosis. Marine drugs. 10: 2181-2207.

Daines, A., R. Payne, M. Humphries and A. Abell, 2003. The synthesis of naturally occurring vitamin $\mathrm{K}$ and vitamin $\mathrm{K}$ analogues. Curr. Org. Chem., 7(16): 1625-1634. 
Dangi, S., S. Dubey, and S. Bh., 2017. Cyanobacterial Diversity: A Potential Source of Bioactive Compounds, Biotech and Micro., 4 (1): 555-627 DOI: 10.19080 /AIBM. 2017.03.555-627.

Devi, K.M. and S.K. Mehta, 2016. Anti-microbial activity and GC-MS analysis of fresh water cyanobacterium Fischerella ambigua. Wjpmr., 2(5): 199-208.

Devi, S.G., A.A. Fathima, S. Radha, R. Arunraj, W.R. Curtis, and M. Ramya, 2015. A rapid and economical method for efficient DNA extraction from diverse soils suitable for metagenomic applications. PLOS.ONE. 10: e0132441. 10.1371/j.pone.0132441.

Gillatt, D., 2006. Anderogen treatment in locally advanced prostate cancer: are they all the same?' J. Cancer Res. Clin. Oncol., 1: 17-26.

Higazy, A.M., 1985. Asymbiotic $\mathrm{N}_{2}$-fixation in Egyptian Aquatic Environment. Ph.D. Thesis, Fac. Agric., Cairo Univ., 123 p.

Konstantinou, D., E. Mavrogonatou, S.K. Zervou, P. Giannogonas, and S. Gkelis, 2020. Bioprospecting sponge-associated marine cyanobacteria to produce bioactive compounds. Toxins, 23:12(2). Pii: E73. doi: 10.3390/ toxins 12020073 PMID :319792 62.

Malathi, T., M.R. Babu, T. Mounika, D. Snehalatha, and B.D. Rao, 2014. Screening of cyanobacteria strains for anti-bacterial activity. Phykos., 44: 6-11.

Marín, I., B.E. Sayas, M.M. Viuda, C. Navarro and E. Sendra, 2016. Chemical composition, anti-oxidant and anti-microbial activity of essential oils from organic fennel, parsley, and lavender from Spain. foods. 5(18) doi:10.3390/foods5010018.

Mericli, F., E. Becer, H. Kabadayi, A. Hanogalu, D.Y. Hanogalu, D.O. Yauus, T. Ozek, and S. Vatansever, 2017. Fatty acid composition and anti-cancer activity in colon carcinoma cell lines of Prunus dulcis seed oil. Pharma. Biol., 55(1): 1239-1248.

Mikulic, M., 2019. Global pharmaceutical industry-statistics and facts. Health \& Pharmaceuticals, Pharmaceutical Products \& Market.

Moares, C., M. Burkert and J. Kalil, 2010. C-phycocyanin extraction process for large-scale use. J. Food Biochem., 34(1): 133-138.

NCCLS, 1997. National Committee for Clinical Laboratory Standards (Performance Standards for Anti-microbial Disk Susceptibility Test $\left(6^{\text {th }}\right.$ ed.). Approved Standard. M100-A6. Wayne, Pensylvania, USA.

Netscher, T., 2007. Synthesis of vitamin E". In vitamin E. vitamins and hormones. 76. (Litwack, Gerald, ed.) pp. 155-202. doi:10.1016/S0083-. ISBN978- 0-12-373592-8.

Newman, D.J. and G.M. Cargg, 2012. Natural products as sources of new drugs over the 30 years from 1981 to 2010. J. Nat. Products, 75: 311-335.

Padma, M., S. Ganesan, T. Jayaseelan, S. Azhagumadhavan, P. Sasikala, S. Senthilkumar, and P. Mani, 2019. Phytochemical screening and GC-MS analysis of bioactive compounds present in ethanolic leaves extract of Silybum marianum (L). J. Drug Delivery and Therapeutics, 9(1): 85-89.

Page, A.L., R.H. Miler, and D.R. Keeny, 1989. Methods of soil analysis part 2 chemical and microbiological properties $2^{\text {nd }}$ ED., American Society of Agronomy, Inc. Soil Science Society of America, Inc., Publisher Madison, Wisconisn USA. 698 p.

Rademaker, J. and F. De Bruijn, 1997. Characterization and classification of microbes by rep-PCR genomic finger printing and computer assisted pattern analysis. DNA markers: protocols, applications and overviews, 151-171. https://www. researchgate.net/ publication/275737873.

Rai, S. V. and M. Rajashekhar, 2015. Anti-oxidant potential of eight species of cyanobacteria isolated from Arabian Sea coast of Karnataka, J. Chem. Pharm. Res., 7(12): 938-942.

Rippka, R., J. Deruelles, J.B. Waterbury, M. Herdman and R.Y. Stanier, 1979. Generic assignments, strain histories and properties of pure cultures of cyanobacteria. J. General Microbiol., 111: 1-61.

Ruberto, G.; M.T. Baratta, D.M. Biondi, and V. Amico, 2001. Anti-oxidant activity of extracts of the marine algal genus Cystoseira in a micellar model system. J. Appl. Phycol., 13: 403-407. 
SAS, 1999. Statistical Analysis System, SAS / STAT User's Guide. Release 6.03 Ed. SAS Institute, Cary, $\mathrm{NC}, 1028 \mathrm{p}$.

Seely, R., J. Duncan, and E. Vidaver, 1972. Preparative and analytical extraction of pigments from brown algae with dimethyl sulfoxide. Mar. Biol., 12: 184-188.

Semary, N.A.E. and M. Fouda, 2015. Anti-cancer activity of Cyanothece sp. strain extracts from Egypt: first record. Asian Pac. J. Trop. Biomed., 5: 992-995. 10.1016/j.apjtb. 2015. 09.004.

Shaieb, F.A., A.A. Issa, and A. Meragaa, 2014. Anti-microbial activity of crude extracts of cyanobacteria Nostoc commune and Spirulina platensis. Arch. Biomed. Sci., 2: 34-41.

Singh, R., P. Parihar, M. Singh, A. Bajagwz, J. Kumar, S. Singh, P.V. Singh and S.M. Prasad, 2017. Uncovering potential applications of cyanobacteria and algal medicine current status and future prospects. Frontiers in Microbiol., 8(515): 1-37.

Singh, R.K., S.P. Tiwari, A.K. Rai and T.M. Mohapatra, 2011. Cyanobacteria: an emerging source for drug discovery. J. Antibiot., 64: 401-412.

Tyagi, T. and M. Agarwal, 2017. Phytoschemical screening and GC-MS analysis of bioactive consititute in the ethanolic extract of Pistia stratiotes L. and Eichhornia crassipes (Mart). Solms J. Pharma. Phytochem., 6(1): 195-206. U.P.B. Sci. Bull. Series B., 73: 4.

Uyeda, J.C., L.J. Harmon and C.E. Blank, 2016. Comprehensive study of cyanobacteria: morphological and ecological evolutionary dynamics through deep geologic time. Plos One, 11(9): 1-32.

Vaara, T., M. Vaara, and S. Niemela, 1979. Two improved methods for obtaining axenic cultures of cyanobacteria. Appl. Env. Microbiol., 1011-1014.

Vijayakumar and M. Menakha, 2015. Pharmaceutical application of cyanobacteria - A review, J. Acute Medicine, 15-23.

Williams, B. W., M. E. Cuveller and C. Berset, 1995. Use of a free-radical methods to evaluate antioxidant activity. LWT Food Sci. Technol., 28: 25-30. 